\title{
Epidemiological Features of Diabetic Retinopathy in Abidjan (Côte d'Ivoire): A Study about 448 Patients
}

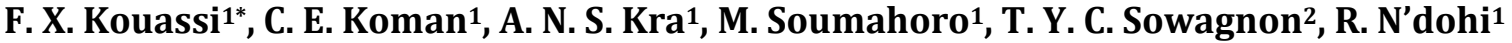 \\ ${ }^{1}$ Ophthalmology Department of Cocody University Hospital, Abidjan, Côte d'Ivoire \\ ${ }^{2}$ Ophthalmology Department of Yopougon University Hospital, Abidjan, Côte d'Ivoire \\ Email: *xavkouassi@yahoo.fr
}

How to cite this paper: Kouassi, F.X., Koman, C.E., Kra, A.N.S., Soumahoro, M., Sowagnon, T.Y.C. and N'dohi, R. (2018) Epidemiological Features of Diabetic Retinopathy in Abidjan (Côte d'Ivoire): A Study about 448 Patients. Open Journal of Ophthalmology, 8, 140-149.

https://doi.org/10.4236/ojoph.2018.83018

Received: June 27, 2018

Accepted: July 30, 2018

Published: August 3, 2018

Copyright $\odot 2018$ by authors and Scientific Research Publishing Inc. This work is licensed under the Creative Commons Attribution International License (CC BY 4.0).

http://creativecommons.org/licenses/by/4.0/

cc) (i) Open Access

\begin{abstract}
Introduction: Diabetic retinopathy is the retinal location of diabetic microangiopathy. It is a public health problem and one of the target diseases of the global Vision 2020 initiative. The aim of our study was to determine the epidemiological features and risk factors of diabetic retinopathy in the melanoderma African in Abidjan. Materials and Methods: We carried out a prospective observational study which took place from April to September 2016 and which focused on the diabetic subjects received in consultation in the Ophthalmology Department of Cocody University Hospital. All Patients had had bio-microscopic examination of the fundus with Goldman three-mirror contact lens and optic coherence tomography of the macula and, in some cases, retinal fluorescein angiography. Results: Out of a population of 448 patients, 200 had diabetic retinopathy. That is a prevalence of $45 \%$. The prevalence of macular edema was $6 \%$. The subpopulation of subjects with retinopathy consisted of $61.5 \%$ (123) of male patients versus $38.5 \%$ (77) of female patients. The mean age of female patients with retinopathy was $42 \pm 14.08$ years and that of male patients $58 \pm 15.07$ years. The majority of patients with retinopathy lived in urban areas (73\%), and had type II diabetes. The duration of evolution of diabetes was 5 to 10 years in $65 \%$ of cases. Obesity, smoking, dyslipidemia and high blood pressure were the main factors of co-morbidity associated with poor glycemic control. Discussion: Diabetic retinopathy had a high prevalence and predominated in males. Maculopathy was represented by macular edema, which is the leading cause of diabetes-related blindness. Conclusion: The prevention of blindness related to diabetes requires regular multidisciplinary follow-up in order to treat retinal damage early.
\end{abstract}

\section{Keywords}

Diabetes, Fundus, Retinopathy, Maculopathy, Optic Coherence Tomography 


\section{Introduction}

Diabetic retinopathy is the retinal location of diabetic microangiopathy. It is a public health problem and one of the target diseases of the global "Vision 2020" initiative. Diabetic macular edema is the leading cause of diabetes-related blindness and the leading cause of blindness before the age of 60 in industrialized countries [1] [2]. Changes in the lifestyle of populations in developing countries, and more particularly in African countries, raise fears of an increase in ocular complications of diabetes. The aim of our study was to determine the epidemiological features and risk factors of diabetic retinopathy in melanoderma African in Abidjan in sight to propose preventive measures and strengthen advocacy for the acquisition of curative treatment resources.

\section{Materials and Methods}

We carried out in the Ophthalmology Department of Cocody University Hospital, a prospective observational study that took place from April to September 2016. We included all diabetic patients (Type 1 or Type 2) received in Ophthalmology consultation during the study period. Each patient had had an ophthalmologic examination with a fundus examination with Goldmann three-mirror contact lens after dilatation. An optical coherence tomography of the macula was performed systematically in all patients in search of macular edema. The classification of ALFEDIAM [3] was used for diabetic retinopathy staging. Gestational diabetes subjects and patients who did not have macular OCT were included in the study in addition to the fundus examination. The duration of diabetes, the glycemic balance and the co-morbidity factors of diabetes in the occurrence of diabetic retinopathy have been studied. Data collection was done on a specific survey form.

The statistical analysis of the data was carried out using the Epi-Info version 3.5.3 software.

\section{Results}

\subsection{Prevalence of Diabetic Retinopathy}

Out of a population of 448 diabetic subjects included in the study, 200 of them had diabetic retinopathy that is a prevalence of $45 \%$ (Figure 1 ). The prevalence of non proliferative diabetic retinopathy was $30.13 \%$ versus $14.51 \%$ of proliferative retinopathy in the diabetic population.

Diabetic retinopathy was observed in $11.27 \%$ of cases in type I diabetics and in $88.72 \%$ of cases in type II diabetics.

\subsection{Prevalence of Different Stages of Diabetic Retinopathy (Table 1)}

We found $67.5 \%$ (135 patients) of non-proliferative diabetic retinopathy and $32.5 \%$ (65 patients) of proliferative diabetic retinopathy among the patients with diabetic retinopathy. 


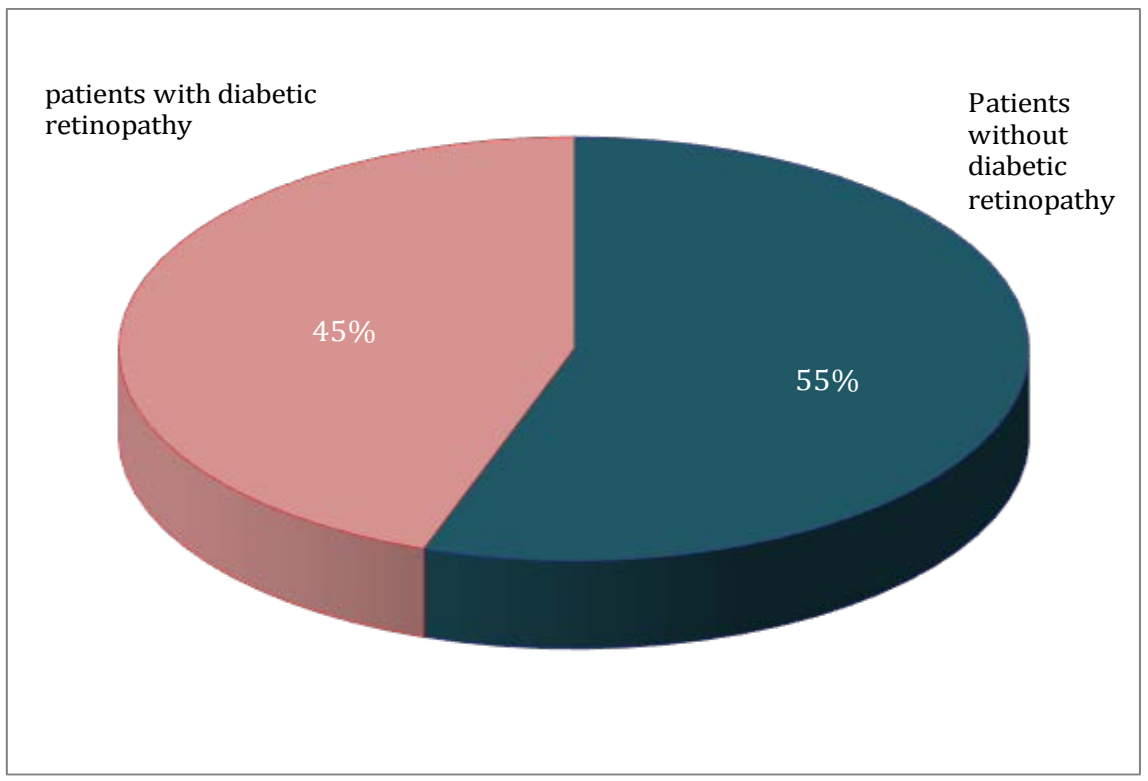

Figure 1. Prevalence of diabetic retinopathy.

Table 1. Prevalence of diabetic retinopathy and maculopathy.

\begin{tabular}{ccc}
\hline Evolutionary stages & Frequencies & Percentages \\
\hline NPDR & 135 & 67.5 \\
Minimal & 53 & 26.5 \\
Moderate & 54 & 27 \\
Severe & 28 & 14 \\
PDR & 65 & 32.5 \\
incipient & 26 & 13 \\
Moderate & 22 & 11 \\
Severe & 11 & 5.5 \\
Complicated & 06 & 03 \\
\hline
\end{tabular}

NPDR: Non-proliferative diabetic retinopathy. PDR: Proliferative diabetic retinopathy.

\subsection{Diabetic Maculopathy}

We did not observe macular ischemia but the prevalence of diabetic macular edema was $5.5 \%$ of the subjects (11 patients) with diabetic retinopathy. Seven patients (3.5\%) were type I diabetics and four (2\%) type II diabetics.

All patients with diabetic macular edema had severe or complicated proliferative diabetic retinopathy.

Macular edema involved 15 eyes of 11 patients and was bilateral in four of them that is $36.36 \%$ of patients with macular edema.

\subsection{Sociodemographic Features of Patients with Diabetic Retinopathy}

\subsubsection{Distribution of Patients by Gender and Age (Table 2)}

The distribution of patients with diabetic retinopathy by gender showed a clear male predominance. Indeed we observed $61.5 \%$ (123) of males versus $38.5 \%$ (77) of females. That is a sex ratio of 1.59 in favor of men. 
Table 2. Distribution of patients by age and sex.

\begin{tabular}{cccc}
\hline Age (years) & Gender & Number & Perrcentages \\
\hline $20-30$ & $\mathrm{M}^{*}$ & 04 & 2 \\
& $\mathrm{~F}^{*}$ & 03 & 1.5 \\
$30-40$ & $\mathrm{M}$ & 13 & 6.5 \\
& $\mathrm{~F}$ & 11 & 5.5 \\
$40-50$ & $\mathrm{M}$ & 49 & 24.5 \\
$50-60$ & $\mathrm{~F}$ & 44 & 22 \\
& $\mathrm{M}$ & 37 & 18.5 \\
& $\mathrm{~F}$ & 12 & 6 \\
& $\mathrm{M}$ & 20 & 10 \\
& F & 07 & 3.5 \\
\hline
\end{tabular}

M: male; F: female; the mean age of women was 42 years \pm 14.08 (38 - 70 years) and that of men 58 years \pm 15.07 (31 - 65 years).

\subsubsection{Area of Usual Residence of Patients (Figure 2)}

$73 \%$ of patients lived in urban areas.

\subsubsection{Level of Education of Patients (Figure 3)}

We found that $48 \%$ of patients with diabetic retinopathy had a university level of education.

\subsection{Type of Diabetes and Glycemic Balance}

The population of patients with diabetic retinopathy was composed of $78 \%$ of subjects $(n=156)$ with type II diabetes and $22 \%$ of subjects $(n=44)$ with type I diabetes.

Patients' mean fasting glucose level was $1.73 \pm 0.83 \mathrm{~g} / \mathrm{l}$ with extremes ranging from 0.71 to 3.76 . Glycated hemoglobin was greater than $6 \%$ in $44.5 \%$ (89) of patients and less than $6 \%$ in $34.5 \%$ (21) of patients. In $21 \%$ (42) of them, the test was not carried out during the study period for financial reasons.

\subsection{Age of Diabetes}

Diabetes was known for less than 5 years in $7 \%(\mathrm{n}=14)$ of patients; it had an age ranging between 5 and 10 years in $65 \%$ of cases $(n=130)$ and greater than 10 years in $28 \%(n=56)$ of cases.

\subsection{Co-Morbidity Factors}

Obesity was the most frequently identified risk factor (56.5\%) in patients with diabetic retinopathy. The average body mass index of obese patients was $33.4 \pm$ $2.1 \mathrm{~kg} / \mathrm{m}^{2}$.

In hypertensive patients (43\%), the mean systolic pressure was $164.5 \pm 39.8$ $\mathrm{mmHg}$ and the mean diastolic pressure was $90.2 \pm 19.4 \mathrm{mmHg}$. 


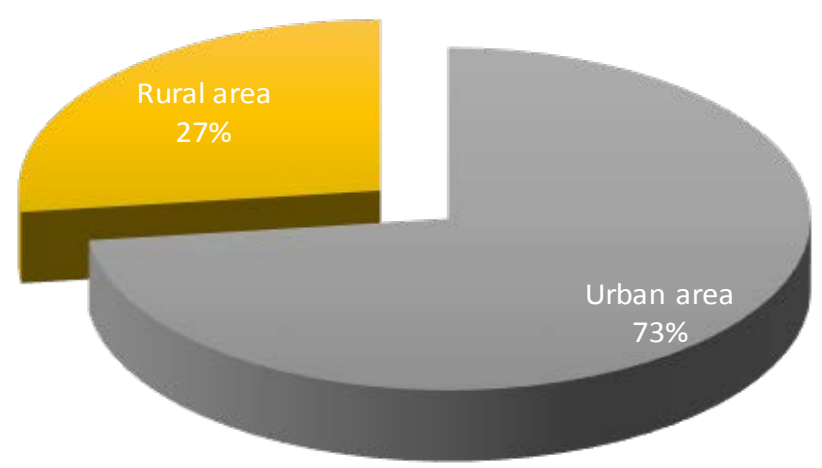

Figure 2. Usual residence of patients.

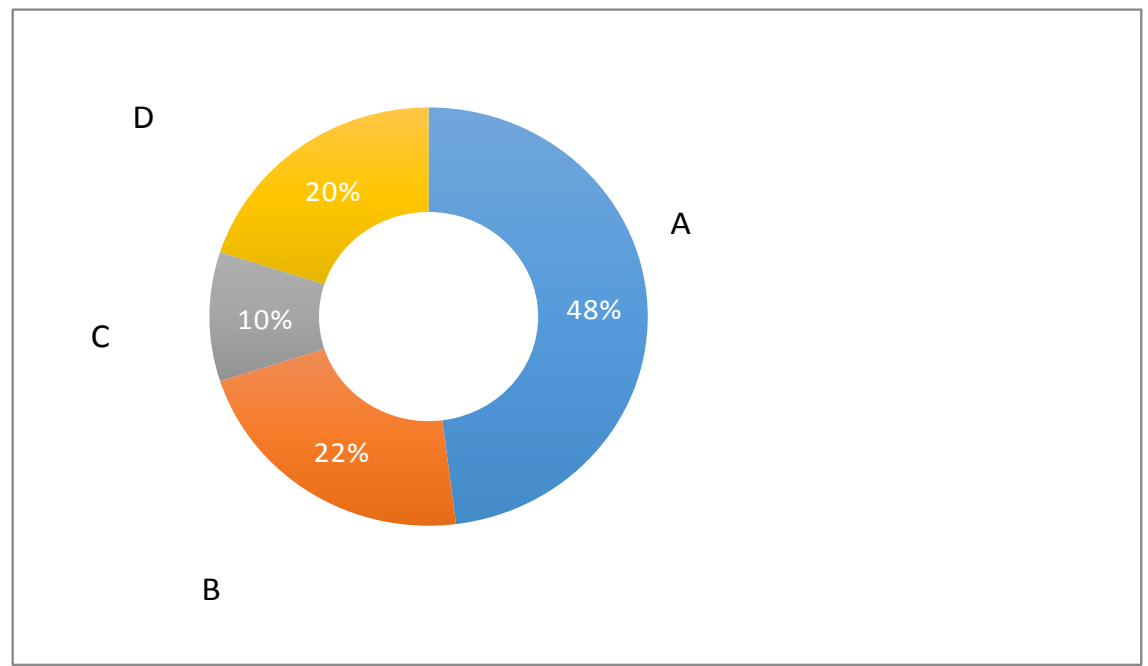

Figure 3. Patients' education level. A: University level; B: Secondary level; C: Primary level; D: Illiterate.

The mean proteinuria of patients with nephropathy (11\%) was $2.5 \pm 0.70 \mathrm{~g} / \mathrm{l}$ and serum creatinine was $66 \pm 26.1 \mathrm{mg} / \mathrm{l}$.

\subsection{Pace of Medical Follow-Up}

The majority of patients (44\%) had an annual follow-up with the diabetologist whereas the pace of ophthalmology consultations was greater than 1 year in 53\% of them.

In addition, the notion of weekly home fasting blood glucose monitoring using a blood glucose meter was found in $16.5 \%(n=33)$ of patients.

\subsection{Therapeutic Management}

The minimal and moderate stages of NPDR have benefited from a balancing of 
blood glucose and other co-morbidities. Severe NPDR and early, moderate, severe, and even complicated PDRs have benefited from argon laser pan-retinal photocoagulation in addition to the previous measures. The proper treatment of TRDs has suffered from the lack of a technical platform for vitreoretinal surgery in our context.

\section{Discussion}

Diabetic retinopathy is the main ophthalmological complication of the diabetic patient and is the leading cause of blindness in people under 60 in industrialized countries [1] [2]. Its prevalence can be estimated through population-based epidemiological studies, ophthalmologist reporting studies, or screening campaigns. The corollary is the variability of the results according to the populations studied, the regions, and the methodology [4] [5]. The number of patients with diabetic retinopathy worldwide was estimated at 93 million in 2012, including 17 million patients with a proliferative form and 21 million with macular edema [6]. A meta-analysis of 35 population-based studies reported a prevalence of diabetic retinopathy, proliferative diabetic retinopathy, and diabetic Maculopathy of $34.6 \%, 7.0 \%$, and $6.8 \%$, respectively [7]. These prevalences are lower than those we observed, which were $45 \%$ for diabetic retinopathy and $14.6 \%$ for the proliferative form (Figure 1, Table 1), with however a prevalence less important of diabetic Maculopathy in our study 5.5\%. The prevalence of diabetic retinopathy that we found, however, is close to that reported by Maroufizadeh [8] who noted in Iran a prevalence of $41.9 \%$ with $32.2 \%$ of non-proliferative retinopathy and $13.2 \%$ of proliferative retinopathy.

Edematous diabetic Maculopathy is the leading cause of blindness in people under 60 in industrialized countries [1] [2] [9]. The prevalence of this serious complication of diabetes also varies according to the studies, regions, and race. In fact, it is around 3\% among Caucasian diabetics in the United States, Europe and Australia, while among Afro-Americans it varies between $8 \%$ and $11 \%$. That is a frequency of 2.5 to 4 times higher than in white persons [6] [10] [11]. In diabetics of Latin American origin, the prevalence of macular edema ranges between 5\% and 10\% [10] [11]. In this study, diabetic macular edema was more common in type I diabetics, as previously reported by Yau [6]. It is important to educate diabetic patients to reduce the prevalence of diabetic retinopathy and maculopathy in our country.

Diabetic retinopathy was more common in males and was predominant in the 40 to 50 age group in both genders (Table 2), joining thus the results of Chatziralli [12]. The high prevalence of diabetic retinopathy in this age group contrasts with the work of Kusnik-Joinville who found a higher prevalence beyond 65 years in France [13]. Our results could be explained by a poor management of diabetes or by its earlier onset. Routine Diabetes Screening could help identify its actual prevalence by age in our context.

This type of diabetes is a risk factor for diabetic retinopathy and Maculopathy. 
In this study, the high prevalence of type II diabetics in patients with retinopathy could be explained by a system of recruitment related to the greater representation of this subpopulation in our sample. These retinal complications of diabetes are more common in type I diabetics [6] [13] [14].

Whatever the type of diabetes, the glycemic balance and duration of the evolution of the disease are important factors in the incidence of diabetic retinopathy. An average blood glucose level of $1.73+/-0.83 \mathrm{~g} / \mathrm{l}$ and a glycated hemoglobin level greater than $6 \%$ in $44.5 \%$ of patients showed poor glycemic control in many patients with diabetic retinopathy in our study. The duration and severity of fasting hyperglycemia as well as high glycated hemoglobin (greater than 6\%) are major factors in the occurrence and progression of diabetic retinopathy. But there is no threshold for glycated hemoglobin below which this risk vanishes [15] [16].

The prevalence of diabetic retinopathy also increases with the age of diabetes to reach, in the best cases, a plateau after 15 to 20 years [13] [14] [15] [16]. However, this retinal complication of diabetes occurs all the more early as the diabetes is poorly controlled [17] and could explain a prevalence of $65 \%$ between 5 and 10 years of age of the disease in our study.

In addition to the age of diabetes, and the glycemic balance, the other risk factors for the occurrence or aggravation of diabetic retinopathy were obesity, smoking, dyslipidemia, alcoholism, cataract surgery, sedentary lifestyle, nephropathy and pregnancy (Table 3). Obesity, sedentary lifestyle and moderate alcohol consumption are not consistently found in studies as risk factors for diabetic retinopathy despite their recognized role in the occurrence of diabetes complications [18]. Smoking was found in $47.5 \%$ of subjects with diabetic retinopathy in our study. It is indeed a risk factor for progression of diabetic retinopathy [19].

High blood pressure is very often associated with diabetes. In the diabetic patient, arterial hypertension, whether systolic or diastolic, is a risk factor for the occurrence of diabetic retinopathy. This association would be linear with an increase in risk of $3 \%$ to $20 \%$ for $10 \mathrm{mmHg}$ increase in systolic blood pressure and $2 \%$ to $30 \%$ in case of a $10 \mathrm{mmHg}$ increase in diastolic blood pressure [20] [21].

As for dyslipidemias, despite the discordant results of some studies, it should be remembered that they constitute risk factors for the occurrence and progression of diabetic retinopathy. Hence the importance of standardizing the lipid balance in diabetics [22] [23] [24].

Diabetic nephropathy is a marker of advanced diabetes. This is a serious micro-vascular complication such as diabetic retinopathy. This explains their frequent correlations [25] [26].

The occurrence of pregnancy in diabetic women is a risk factor for the onset or aggravation of diabetic retinopathy, particularly since there is pre-existing advanced retinopathy, whether there is arterial hypertension or preeclampsia [19] [27]. 
Table 3. Co-morbidity factors in patients with diabetic retinopathy.

\begin{tabular}{ccc}
\hline Co-morbidity factors & Frequency & percentage \\
\hline Obesity & 113 & 56.50 \\
Smoking & 95 & 47.50 \\
High Blood Pressure & 86 & 43.00 \\
Dyslipidemia & 83 & 41.50 \\
Alcoholism & 51 & 25.50 \\
Cataract surgery & 38 & 19.00 \\
Sedentary lifestyle & 30 & 15.00 \\
Nephropathy & 22 & 11.00 \\
Pregnancy & 11 & 5.50 \\
\hline
\end{tabular}

Table 4. Pace of follow-up visits with the diabetologist and ophthalmologist.

\begin{tabular}{ccccc}
\hline & Quaterly & Half-yearly & Annual & $>1$ an \\
\hline Diabetologist & $7.5 \%(15)$ & $17 \%(34)$ & $44 \%(88)$ & $31.5 \%(63)$ \\
Ophtalmologist & $5.5 \%(11)$ & $12 \%(24)$ & $29.5 \%(59)$ & $53 \%(106)$ \\
\hline
\end{tabular}

A history of cataract surgery was found in $19 \%$ of our patients with diabetic retinopathy. Cataract surgery is a risk factor for the onset or aggravation of diabetic retinopathy. It is therefore imperative to stabilize diabetes before any cataract surgery in diabetics [19] [28].

In addition, our study has revealed a poor medical follow-up of diabetic patients with an annual diabetological consultation at most in $75.5 \%$ of patients which led to poor ophthalmological follow-up (Table 4).

So, the poor glycemic balance, and the other co-morbidity factors we studied can explain the early onset of diabetic retinopathy in the study population

\section{Conclusion}

At the end of this study, we know that the prevalence of diabetic retinopathy was $45 \%$. It predominated in males and was more prevalent in the 40 to 50 age group. Poor glycemic control, obesity, smoking and high blood pressure were the most common risk factors. They explain an early onset of diabetic retinopathy between 5 and 10 years of age. Reducing diabetes blindness requires an awareness of diabetic patients to better diabetological and ophthalmological follow-up. Sensitization and screening campaigns are to be carried out at least annually to improve the management of diabetes and these complications in Abidjan.

\section{Institution of Origin of the Study}

Ophthalmology Department of Cocody University Hospital-Abidjan. 


\section{Conflict of Interest}

The authors declare no conflicts of interest regarding the publication of this paper.

\section{References}

[1] Parrajasegaram, R. (1999) Vision 2020-The Right to Sight: From Stratégies to Action. American Journal of Ophthalmology, 128, 359-360.

[2] Organisation mondiale de la santé (2016) Rapport mondial sur le diabète. Genève.

[3] Massin, P., Angioi-Duprez, K., Bacin, F., et al. (1996) Dépistage, surveillance et traitement de la rétinopathie diabétique. Recommandations de l'ALFEDIAM. Diabetes \& Metabolism, 22, 203-209.

[4] Klein, R. (1996) Diabetic Retinopathy. Annual Review of Public Health, 17, 137-158. https://doi.org/10.1146/annurev.pu.17.050196.001033

[5] Klein, R., Klein, B.E. and Moss, S.E. (2001) How Many Steps of Progression of Diabetic Retinopathy Are Meaningful? The Wisconsin Epidemiologic Study of Diabetic Retinopathy. Archives of Ophthalmology, 119, 547-553. https://doi.org/10.1001/archopht.119.4.547

[6] Yau, Y.W., Rogers, S.L., Kawasaki, R., Lamoureux, E.L., et al. (2012) Global Prevalence and Major Risk Factors of Daibetic Retinopathy. Diabetes Care, 35, 556-564. https://doi.org/10.2337/dc11-1909

[7] Zheng, Y., He, M. and Congdon, N. (2012) The Worldwide Epidemic of Diabetic Retinopathy. Indian Journal of Ophthalmology, 60, 428-431.

[8] Maroufizadeh, S., Almasi-Hashiani, A., Hosseini, M., Sepidarkish, M. and Omani, S.R. (2017) Prevalence of Diabetic Retinopathy in Iran: A Systematic Review and Meta-Analysis. International Journal of Ophthalmology, 10, 782-789.

[9] Ciulla, T.A., Amador, A.G. and Zinman, B. (2003) Diabetic Retinopathy and Diabetic Macular Edema/Pathophysiology, Screenning and Novel Therapies. Diabètes Care, 26, 2653-2664. https://doi.org/10.2337/diacare.26.9.2653

[10] Wong, T.Y., Klein, R., Islam, F.M., et al. (2006) Diabetic Retinopathy in a Multicentric Cohort in the United States. American Journal of Ophthalmology, 141, 446-451. https://doi.org/10.1016/j.ajo.2005.08.063

[11] Varma, R., Bressler, N.M., Doan, Q.V., et al. (2014) Prevalence and Risk Factors for Diabetic Macular Edema in the United States. JAMA Ophthalmology, 132, 1334-1340. https://doi.org/10.1001/jamaophthalmol.2014.2854

[12] Chatziralli, I., Sergentanis, T.N., Crosby-Nwaobi, R., et al. (2017) Model for Risk-Based Screening of Diabetic Retinopathy in a People with Newly-Diagnosed Type 2 Diabèetes Mellitus. Investigative Ophthalmology \& Visual Science, 58, 99-105. https://doi.org/10.1167/iovs.17-21713

[13] Kusnik-Joinville, O., Weil, A., Ricordeau, P., et al. (2008) Diabète traité en France en 2007: Un taux de prévalence proche de $4 \%$ et des disparités géographiques croissantes. Bull Epidemiol Hebd, 43, 409-413.

[14] Ou, H.T., Lee, T.Y., Li, C.Y., et al. (2017) Incidence of Diabetes-Related Complications in Chinese Patients with Type 1 Diabetes: A Population-Based Longitudinal Cohort Stufy in Taiwan. BMJ Open, 7, e015117.

[15] The Diabetes Control and Complications Trial Research Group (1995) The Relationship of Glycemic Exposure $\left(\mathrm{HbA}_{1 \mathrm{C}}\right)$ to the Risk of Development and Progression of Retinopathy in the Diabètes Control and Complications Trial. Diabetes, 44, 
968-983. https://doi.org/10.2337/diab.44.8.968

[16] Cardoso, C.R.L., Leite, N.C., Dib, E. and Salles, G.F. (2017) Predictors of Development and Progression of Retinopathy in Patients with Type 2 Diabetes: Importance of Blood Pressure Parameters. Scientific Reports, 7, Article No. 4867. https://doi.org/10.1038/s41598-017-05159-6

[17] Sasongko, M.B., Widyaputri, F., Agni, A.N., et al. (2017) Prevalence of Diabetic Retinopathy and Blindness in Indonesian Adults with Type 2 Diabetes. American Journal of Ophthalmology, 181, 79-87. https://doi.org/10.1016/j.ajo.2017.06.019

[18] Zhou, Y., Zhang, Y., Shi, K., et al. (2017) Body Mass Index and Risk of Diabetic Retinopathy: A Meta-Analysis and Systematic Review. Medicine (Baltimore), 96, e6754.

[19] Kramer, C.K., Azevedo, M.J., Da Costa Rodrigues, T., et al. (2008) Smoking Habit Is Associated with Diabetic Macular Edema in Type 1 Diabetes Mellitus Patients. Journal of Diabetes and Its Complications, 22, 430. https://doi.org/10.1016/j.jdiacomp.2007.07.005

[20] Gallego, P.H., Craig, M.E., Hings, S., et al. (2008) Role of Blood Pressure in Development of Early Retinopathy in Adolescents with Type 1 Diabetes: Prospective Cohort Study. British Medical Journal, 337, a918. https://doi.org/10.1136/bmj.a918

[21] Gupta, A., Raman, R., Kulothungan, V., et al. (2014) Association of Systemic and Ocular Risk Factors with Neurosensory Retinal Detachment in Diabetic Macular Edema: A Case-Control Study. BMC Ophthalmology, 9, 14-47. https://doi.org/10.1186/1471-2415-14-47

[22] Hadjadj, S., Duly-Bouhanick, B., Bekherraz, A., et al. (2004) Serum Triglycerides Are Predictive Factor for the Development and Progression of Complications in $\mathrm{Pa}$ tients with Type 1 Diabetes. Diabetes \& Metabolism, 30, 43-51. https://doi.org/10.1016/S1262-3636(07)70088-5

[23] Klein, B.E., Myers, C.E., Howard, K.P. and Klein, R. (2015) Serum Lipids and Proliferative Diabetic Retinopathy and Macular Edema in Persons with Long-Term Type 1 Diabetes Mellitus: The Wisconsin Epidemiologic Study of Diabetic Retinopathy. JAMA Ophthalmology, 133, 503-510. https://doi.org/10.1001/jamaophthalmol.2014.5108

[24] Morton, J., Zoungas, S., Li, Q., et al. (2012) Low HDL Cholesterol and the Risk of Diabetic Nephrapathy and Retinopathy: Results of the Advance Study. Diabetes Care, 35, 2201-2206. https://doi.org/10.2337/dc12-0306

[25] Bouaziz, A., Zidi, I., Zidi, N., et al. (2012) Nephropathy Following Type 2 Diabetes Mellitus in Tunisian Population. West Indian Medical Journal, 61, 881-889.

https://doi.org/10.7727/wimj.2012.053

[26] Ganjifrockwala, F.A., Joseph, J.T. and George, G. (2017) Evaluation of Kidney Function and Risk Factors of Retinopathy in Type 2 Diabetes Mellitus People in South Africa. Diabetes Research and Clinical Practice, 127, 218-223. https://doi.org/10.1016/j.diabres.2017.03.022

[27] Booth, G. and Cheng, A.Y. (2013) Canadian Diabetes Association 2013 Clinical Practice Guidelines for the Prevention and Management of Diabetes in Canada. Methods Canadian Journal of Diabetes, 37, S4-S7. https://doi.org/10.1016/j.jcjd.2013.01.010

[28] Kim, S.J., Equi, R. and Bressler, N.M. (2007) Analysis of Macular Edema after Cataract Surgery in Patients with Diabetes Using Optical Coherence Tomography. Ophthalmology, 14, 881-889. https://doi.org/10.1016/j.ophtha.2006.08.053 